\title{
AS BARREIRAS EXISTENTES NA TRANSFERÊNCIA DO CONHECIMENTO DURANTE O PROCESSO DE APRENDIZAGEM: Um estudo realizado com alunos de um curso de graduação em Ciências Contábeis
}

Letícia Rodrigues da FONSECA ${ }^{1}$ Marcelo Ribeiro SILVA ${ }^{2}$

Sheldon William SILVA ${ }^{3}$

Guilherme Marques PEREIRA ${ }^{4}$

\begin{abstract}
${ }^{1}$ Doutora em Administração pela Universidade Presbiteriana (UPM). Professora na Universidade Vale do Rio Verde (UNINCOR). leticia.rodrigues.vga@gmail.com

${ }^{2}$ Doutor em Administração pela Universidade Presbiteriana Mackenzie (UPM). Professor na Universidade Federal do Mato Grosso do Sul (UFMS).

${ }^{3}$ Mestre em Administração pela Faculdade Pedro Leopoldo. Professor no Centro Universitário do Sul de Minas.

${ }^{4}$ Mestre em Administração pela Campanha Nacional de Escolas da Comunidade (CNEC). Professor na Faculdade Cenecista de Varginha (FACECA).
\end{abstract}

Recebido em: 10/07/2016 - Aprovado em: 15/12/2016 - Disponibilizado em: 18/12/2016

\begin{abstract}
RESUMO
Com o intuito de oferecer informações que possam atuar como subsídio aos Programas de Qualificação de Docentes, este estudo tem como objetivo identificar quais as barreiras presentes na transferência de conhecimento durante o processo de ensino-aprendizagem, no momento do desenvolvimento dos trabalhos de conclusão de curso. Para isso, realizou-se um estudo exploratório descritivo, com abordagem quantitativa com 82 formandos de um curso Superior em Ciências Contábeis oferecido por uma instituição privada localizada no Estado de Minas Gerais. Considerou-se como hipótese: o conhecimento prévio sobre o desenvolvimento de pesquisas acadêmicas reduz barreiras na transferência de conhecimento na relação entre professor e aluno. Utilizou-se como instrumento de coleta de dados um questionário elaborado segundo as definições das nove barreiras presentes na transferência do conhecimento, apresentadas por SZULANSKI (1995,1996).Os resultados demonstraram que o conhecimento prévio sobre o desenvolvimento de pesquisas acadêmicas não reduz as barreiras "ambigüidade causal", "falta de prova de utilidade do conhecimento da fonte", "falta de motivação da fonte" e "falta de confiabilidade percebida da fonte". No entanto, identificou-se que o conhecimento prévio tende a reduzir as barreiras "falta de motivação do receptor", "falta de capacidade de absorção do receptor", "falta de capacidade de retenção do receptor", "contexto organizacional estéril”, e "difícil relacionamento entre fonte e receptor" considerando o aspecto empatia. Os resultados obtidos abordaram ainda questões importantes que merecem reflexão, como a criação de uma cultura que incentive a pesquisa e a importância do conhecimento, bem como a importância de um bom relacionamento entre professor e aluno durante o processo de ensino-aprendizagem.

Palavras-chave: Barreiras na Transferência de Conhecimento; Processo de Ensino-Aprendizagem
\end{abstract}

\section{THE EXISTING BARRIERS IN THE TRANSFER OF KNOWLEDGE} DURING THE LEARNING PROCESS: a study conducted with the students of

\section{a graduation in Accounting Sciences}

\begin{abstract}
In order to offer information that can be used as a subsidy to programs of Teachers' Qualification, this study aims to identify which barriers existent in the transference of knowledge during the teaching-learning process, at the time of the development of the end-of-program paper. Due to that, it was conducted an exploratory descriptive study, with a
\end{abstract}


quantitative approach involving 82 senior students from a Accountancy Science course offered by a college located in the State of Minas Gerais. It was taken into account as hypothesis: prior knowledge on the development of academic research reduces barriers in the transference of knowledge in the relationship between teacher and student. As an instrument of data collection it was applied a questionnaire set up according to the nine-barrier definitions present in the transmission of knowledge, submitted by SZULANSKI (1995.1996). The results revealed that the previous knowledge on the development of academic research does not reduce the barriers "causal equivocation", "lack of proof of utility of knowledge of the source", "lack of motivation of the source" and "lack of reliability perceived the source". However, it was pointed out that the previous knowledge tends to reduce the barriers: "lack of motivation of the receiver", "lack of absorption capacity of the receiver", "lack of retention capacity of the receiver", "sterile organizational context", and "difficult relationship between source and receiver" taking into account the empathy aspect. The results obtained also approached important issues that deserve reflection, as the creation of a culture which encourages the research and the importance of knowledge, as well as the importance of a good relationship between professor and student over the teaching-learning process.

Keywords: Barriers in the Transference of Knowledge; Teaching-Learning Process.

\section{INTRODUÇÃO}

O ensino universitário tende a ser visto como um processo de aprendizagem baseado na aquisição de conhecimento teórico, na incorporação de habilidades que permitam a crítica de tal conhecimento e na habilidade de agir em função desse conhecimento. Diante deste contexto, começa-se a questionar e a avaliar o ensino universitário, o que ocasiona, por parte das IESs - Instituições de Ensino Superior, a preocupação quanto às metodologias de ensino adotadas para o desenvolvimento destas competências. No processo de ensinoaprendizagem, o educador irá lidar com o ser humano, sendo assim, trabalhará constantemente com possibilidades, imprevistos e incertezas. Não poderá obrigar o aluno a aprender, devendo, portanto fazer uso de meios que facilitem o seu aprendizado, conduzindo-o em direção aos objetivos daquela aula, daquele conjunto de aulas ou daquele curso (ABREU E MASSETTO, 1983).

Acredita-se que durante o aprendizado em sala de aula o aluno deverá ser capaz de absorver o conhecimento exposto, bem como saber aplicá-lo na prática, em sua realidade. No entanto, esta absorção poderá ser comprometida devido ao surgimento de determinadas barreiras durante a transferência do conhecimento. A transferência de conhecimento tende a ser "viscosa" (difícil), por diversos fatores, incluindo a natureza do conhecimento e as escolhas e atributos de seus buscadores e provedores (SZULANSKI, 2003).

Diante deste contexto, o objetivo do presente estudo é identificar quais as barreiras presentes na transferência de conhecimento durante o processo de ensino-aprendizagem no momento do desenvolvimento dos trabalhos de conclusão de um curso de graduação em Ciências Contábeis. Para Macohon (2006), a contabilidade vem 
ocupando espaço na sociedade em razão de sua evolução na administração e controle dos recursos nas organizações. A preocupação com a formação profissional dos alunos de IES, no que concerne à formação acadêmica e prática profissional da contabilidade é cada vez mais evidente, ao analisar as perspectivas do mercado de trabalho.

Optou-se por estudar o processo de ensino-aprendizagem durante a orientação dos trabalhos de conclusão de curso, visto que neste momento a relação entre professor e aluno será mais estreita. Acredita-se que esta proximidade irá possibilitar uma percepção mais confiável por parte do educando sobre as barreiras encontradas durante a absorção do conhecimento.

Espera-se ao final, contribuir com informações que possam subsidiar os Programas de Qualificação de Docentes que visam obter resultados mais satisfatórios no processo de ensino-aprendizagem. Para Tachizawa e Andrade (2002), as IESs necessitam investir continuamente no desenvolvimento de seus colaboradores por meio de educação, treinamento e oportunidades, visando crescimento permanente de cada um e da própria instituição. Para a realização de qualquer atividade que vise o desenvolvimento dos profissionais da IES, é necessário a coleta de informações quanto às suas habilidades, seu desenvolvimento, sua motivação, entre outros aspectos.

\section{REFERENCIAL TEÓRICO}

\subsection{Conceituando Conhecimento}

De acordo com Nonaka e Takeuchi (1997), existem duas grandes tradições epistemológicas na filosofia ocidental: o racionalismo e o empirismo. $\mathrm{O}$ racionalismo argumenta que o verdadeiro conhecimento não é o produto da experiência sensorial, mas sim, um processo mental ideal. Segundo essa visão, existe um conhecimento a priori que não precisa ser justificado pela experiência sensorial. Ao contrário, deduz-se a verdade absoluta a partir de uma argumentação racional baseada em axiomas. A matemática é um exemplo clássico desse tipo de argumentação.

Por outro lado, segundo os autores, o empirismo alega que não existe conhecimento a priori e que a única fase de conhecimento é a experiência sensorial. De acordo com essa visão, tudo no mundo tem uma existência intrinsecamente objetiva, mesmo quando se tem uma percepção ilusória. A ciência experimental é o exemplo clássico dessa visão.

Essas duas principais abordagens à epistemologia, diferem radicalmente quanto ao que constitui a verdadeira fonte de conhecimento.

Para os autores, outra diferença fundamental é o método por meio do qual se obtém o conhecimento. A corrente racionalista alega que se pode obter o 
conhecimento por "dedução", recorrendo-se a constructos mentais como conceitos, leis ou teorias. E a corrente empirista, argumenta que o conhecimento é obtido por "indução", a partir de experiências sensoriais específicas.

Segundo Abreu (2001), a aplicação do conhecimento se deu com o surgimento das invenções, das máquinas entre outros recursos que viabilizaram a era industrial e a do conhecimento (NAISBITT, 1982; SENGE, 1990; DRUCKER; 2000; SANTIAGO JUNIOR, 2001).

Desta forma, o conhecimento passou de um recurso que permitia atingir um resultado para um elemento de estudo, cuja pesquisa foca a sua criação como as suas formas de utilização para se obter melhores resultados.

Surge assim, a Gestão do Conhecimento, que nas palavras de Fuller (2002), ao sugerir que o conhecimento deve literalmente ser administrado, pretende-se, na realizada, evitar que o referido não seja negligenciado, pois na melhor das hipóteses o conhecimento pode não ser utilizado, no entanto, na pior, pode ser desperdiçado.

Autores contemporâneos contribuíram com novas associações entre conhecimento, método e aprendizagem (BELL, 1973; DRUCKER, 1994; TOFLER, 1980; O`DELL e GRAYSON, 1998), alguns defendendo que a base do conhecimento é a experiência e outros que sua aplicação se dá em ações práticas.
Dixon (2000), trata o conhecimento como ligações de sentido entre a informação e sua aplicação prática na mente humana.

A base do conhecimento que promove o aprendizado se inicia a partir do momento em que o indivíduo busca a sua evolução de acordo com fatores motivacionais primários de sobrevivência presentes em seu cotidiano. Esse conhecimento é intuitivo e surge no contexto local, cercados pelos fatores ambientais abstraído pelos sentidos do ser humano BRONOWSKI,(1997).

\subsection{Taxonomias de Conhecimento}

Para Connel et al (2003), existem diversas taxionomias utilizadas para se refinar as idéias sobre conhecimento. Os autores apresentam dois tipos de conhecimento: tácito (ou implícito que envolve insights e habilidades menos especificáveis "incorporadas" em indivíduos, ou em contextos organizacionais) e o explícito (que envolve conceitos, informações e insights, especificáveis e formalizáveis por meio de regras e procedimentos).

$\mathrm{Na}$ mesma linha de pensamento Nonaka e Takeuchi (1997), apresentam os conhecimentos do tipo tácito e explícito de uma maneira mais detalhada. O tácito sendo difícil de ser articulado na linguagem formal, trata-se do tipo de conhecimento mais importante, é o conhecimento pessoal incorporado à experiência individual e 
envolve fatores intangíveis como crenças pessoais, perspectivas e sistemas de valor. $\mathrm{O}$ explícito, pode ser articulado na linguagem formal, inclusive em afirmações gramaticais, expressões matemáticas, especificações, manuais, etc. Pode ser transmitido formalmente e facilmente entre os indivíduos.

Collins (1993), apresenta uma taxionomia formada por quatro tipos de conhecimento, simbólico (o formal), o incorporado (conhecimento tácito que reside nas rotinas e normas compartilhadas), $\mathrm{o}$ cerebral (relacionado às habilidades conceitual e cognitiva do indivíduo) e o aculturado (obtido por meio das interações com os grupos nos quais estamos inseridos).

Ao analisar todas as taxionomias apresentadas pode-se constatar que $\mathrm{o}$ conhecimento tácito é o mais importante e o mais difícil de ser transferido, principalmente pelo fato de ser idiossincrático (NOOTEBOOM e GILSING, 2002). No entanto, para que haja uma transferência de conhecimento efetiva é necessário identificar e excluir os "ruídos" que impedem a transmissão do conhecimento tácito e a sua institucionalização. As IES buscam atingir esse objetivo no processo ensinoaprendizagem.

Choo (2003) afirma que apesar do conhecimento tácito não ser codificado, este pode ser ensinado e compartilhado. O conhecimento tácito pode ser aprendido por meio de exemplo de situações como compartilhado por meio de formas ricas de discurso, que incluem o uso de analogias, metáforas ou modelos.

\subsection{Transferência de Conhecimento}

Compartilhar e transferir trata-se de um processo em que se permite a transmissão, a absorção e o conseqüente uso do conhecimento (DAVENPORT e PRUSSAK, 1998). Para Cohen e Levinthal (1990), a absorção do conhecimento refere-se a capacidade de internalizar novos conhecimentos. Existem dois fatores críticos de sucesso relacionados a este processo, a velocidade e a viscosidade. A velocidade trata-se da rapidez que o conhecimento flui na organização, já a viscosidade refere-se ao grau de riqueza ou densidade do conhecimento transferido (DAVENPORT e PRUSSAK, 1998).

Para que o processo de transferência de conhecimento seja realizado de uma maneira eficaz é necessário que as pessoas estejam cientes da importância da partilha do conhecimento.

Argote e Ingram (2000), afirmam que os indivíduos que não compreendem a importância da partilha de conhecimento não conseguem se comunicar da maneira adequada com os outros indivíduos, comprometendo o processo de transferência.

Devido a essa afirmação, acredita-se que a cultura organizacional seja fundamental 
no processo de compartilhamento de conhecimento. Davenport e Prusak (1998), afirmam que os indivíduos que compartilham a mesma cultura podem se comunicar melhor além de transferir conhecimento, de forma mais eficiente em relação àquelas que não compartilham.

Dixon (2000), salienta que deve-se considerar três aspectos-chaves na escolha do sistema de gestão e transferência do conhecimento: as características do receptor pretendido, em termos de similaridade de tarefas e contexto; a natureza da tarefa, em termos de quão frequente e rotineira ela é realizada; tipo de conhecimento a ser transferido.A autora apresenta ainda as cinco formas de transferência do conhecimento: transferência serial (serial transfer) - a equipe que realiza uma tarefa repete sua realização em um contexto diferente; transferência próxima (near transfer) - transferência de conhecimento de uma equipe para outra que esteja realizando uma tarefa semelhante, em um contexto semelhante, no entanto, em local diferente; transferência distante (far transfer) - transferência de conhecimento tácito de uma equipe para outra, na qual a tarefa não é rotineira; transferência estratégica (strategic transfer) - transferência de conhecimento complexo de uma equipe a outra, separadas tanto no tempo quanto no espaço; transferência especializada (expert transfer) transferência de conhecimento explícito sobre uma tarefa rotineira.
Alavi e Leidner (2001), baseando-se na sociologia do conhecimento apresentada por Berger e Luckman (1985), concluíram que as organizações são como sistemas do conhecimento, constituídas por quatro processos sociais: criação do conhecimento; armazenamento e recuperação do conhecimento; transferência do conhecimento; aplicação do conhecimento. Matusik (2002) argumenta, que a maneira como estes processos ocorrem irão afetar o nível de conhecimento global da organização.

De acordo com Shaw e Perkins (1993), a capacidade de transferir e disseminar conhecimento é conseguida quando há um intercâmbio colaborativo de idéias no qual perspectivas diferentes são expostas e o conhecimento é partilhado.O processo de transferência do conhecimento nada mais é, do ponto de vista de quem está recebendo a transferência, do que uma aprendizagem.

\subsection{Barreiras à Transferência do Conhecimento}

Szulanski (1995), criou o termo stickiness (viscosidade), que significa: a dificuldade em transferir conhecimento. Essa dificuldade pode ser encontrada nas atividades que exigem resolução de problemas relacionados à inovação, no grau de transmissão e de utilização de conhecimento ou na habilidade da empresa 
em se desenvolver por meio da réplica de competências e habilidades já existentes.

Em seu artigo publicado em 1995, Szulanski apresentou os resultados de uma investigação empírica sobre as origens de stickness nas empresas. Para isso, ele realizou um estudo sobre a transferência das melhores práticas dentro da organização.

Ao discutir as barreiras da transferência de melhores práticas, Szulanski se baseou no estudo de Arrow (1962), sobre dois fatores que poderiam limitar a transferência de conhecimento: a credibilidade da fonte e a habilidade do receptor em decifrar a mensagem.

Szulanski aprimorou o estudo de Arrow, ao incorporar os quatro componentes essenciais para a comunicação: fonte, receptor, mensagem (conhecimento transferido) e o meio (contexto).

Assim, Szulanski apresentou nove proposições, dentre as quais duas são referentes às características do conhecimento transferido e as outras sete referentes às características do contexto de transferência. As proposições expressam que todas as características mencionadas são positivamente correlacionadas com o stickiness.

Para testar as suas hipóteses, Szulanski realizou uma pesquisa na qual enviou um questionário que foi respondido por 8 empresas: AMP, AT\&T Paradyne, British Petroleum, Burmah Castrol, Chevron Corporation, EDS, Kaiser
Permanente e Rank Xerox. A variável dependente era o stickiness e as variáveis independentes as fontes de stickiness. Os resultados obtidos sugeriram que os principais determinantes da manifestação das conseqüências do stickiness eram a falta de capacidade de absorção do receptor, o relacionamento difícil entre fonte e receptor e a falta de motivação do receptor. Outros dois fatores, embora importantes, apresentaram correlação oposta com o stickiness: a falta de motivação da fonte e a falta de capacidade de retenção do receptor. Os demais fatores não apresentaram correlações significantes. Szulanski concluiu que as principais fontes do stickiness estão nos atributos do contexto. O Quadro 1, apresenta as nove barreiras, separadas em quatro categorias, com os seus respectivos conceitos, além de expor os autores-chaves utilizados por Szulanski para a definição dos referidos conceitos. 
Quadro 1 - Barreiras à Transferência do Conhecimento

\begin{tabular}{|c|c|c|c|}
\hline \multicolumn{4}{|c|}{ Barreiras à Transferência de Conhecimento } \\
\hline CATEGORIA & BARREIRA & CONCEITO & $\begin{array}{l}\text { AUTORES- } \\
\text { CHAVES } \\
\text { UTILIZADOS POR } \\
\text { (SZULANSKI } \\
\text { 1995, 1996) }\end{array}$ \\
\hline \multirow[t]{2}{*}{$\begin{array}{l}\text { Características } \\
\text { do } \\
\text { Conhecimento } \\
\text { Transferido }\end{array}$} & $\begin{array}{l}\text { Ambiguidade } \\
\text { causal }\end{array}$ & $\begin{array}{l}\text { Não se consegue determinar, exatamente, quais foram } \\
\text { as razões para o sucesso ou fracasso. Não é possível identificar, } \\
\text { com precisão, qual foi a melhor prática. A ambigüidade causal } \\
\text { ofusca como os aspectos do novo ambiente afetam os resultados } \\
\text { da réplica de conhecimento, contribuindo para o stickiness. }\end{array}$ & $\begin{array}{l}\text { - Lippman e Rumelt } \\
\text { (1982) } \\
\text { - Polianyi (1962) } \\
\text { - Winter (1987) } \\
\text { - Winter (1995) } \\
\text { - Kogut e Zander } \\
\text { (1992) } \\
\text { - Spender (1993) } \\
\text { - Nonaka (1994) } \\
\text { - Grant (1996) }\end{array}$ \\
\hline & $\begin{array}{l}\text { Falta de prova } \\
\text { de utilidade do } \\
\text { conhecimento } \\
\text { da fonte }\end{array}$ & $\begin{array}{l}\text { A falta de provas quanto a utilidade do conhecimento pode gerar } \\
\text { dificuldades na busca pela participação do receptor no processo } \\
\text { de transferência. Ao se buscar transferir uma prática } \\
\text { desenvolvida recentemente o receptor pode não confiar que esse } \\
\text { conhecimento seja eficaz em uma nova situação. }\end{array}$ & $\begin{array}{l}\text { - } \\
\text { Goodman;Bazerman; } \\
\text { Conlon (1980) } \\
\text { - Nelson e Winter } \\
(1982)\end{array}$ \\
\hline \multirow[t]{2}{*}{$\begin{array}{l}\text { Características } \\
\text { da Fonte }\end{array}$} & $\begin{array}{l}\text { Falta de } \\
\text { motivação da } \\
\text { fonte }\end{array}$ & $\begin{array}{l}\text { Pode dificultar a transferência caso a fonte não queira } \\
\text { compartilhar o seu conhecimento por medo de perder o domínio } \\
\text { sobre este ou por medo deste compartilhamento gerar } \\
\text { competição. Pode acontecer ainda, quando a fonte não quer } \\
\text { dedicar seu tempo e esforço na transferência de conhecimento } \\
\text { para outrem. }\end{array}$ & $\begin{array}{l}\text { - Arrow (1971) } \\
\text { - Perloff (1993) }\end{array}$ \\
\hline & $\begin{array}{l}\text { Falta de } \\
\text { confiabilidade } \\
\text { percebida da } \\
\text { fonte }\end{array}$ & $\begin{array}{l}\text { Uma fonte confiável influi positivamente no comportamento do } \\
\text { receptor, não apresentando resistências quanto ao conhecimento } \\
\text { que está sendo transferido. }\end{array}$ & $\begin{array}{l}\text { - Perloff (1993) } \\
\text { - Walton (1975) }\end{array}$ \\
\hline \multirow[t]{3}{*}{$\begin{array}{l}\text { Características } \\
\text { do Receptor }\end{array}$} & $\begin{array}{l}\text { Falta de } \\
\text { motivação do } \\
\text { receptor }\end{array}$ & $\begin{array}{l}\text { O receptor precisa estar motivado para que a transferência de } \\
\text { conhecimento ocorra de maneira eficaz. Alguns receptores } \\
\text { apresentam a síndrome do "não foi inventado aqui", o que } \\
\text { ocasiona a rejeição do conhecimento gerado fora da empresa ou } \\
\text { de sua unidade. }\end{array}$ & $\begin{array}{l}\text { - Hayes e Clark } \\
(1985) \\
\text { - Katz e Allen (1982) } \\
\text { - Zaltman; } \\
\text { Duncan;Holbek, } \\
\text { (1973) }\end{array}$ \\
\hline & $\begin{array}{l}\text { Falta de } \\
\text { capacidade de } \\
\text { absorção do } \\
\text { receptor }\end{array}$ & $\begin{array}{l}\text { Irá depender de quanto conhecimento prévio o receptor possui } \\
\text { sobre o assunto. Quanto menor o conhecimento prévio, menor } \\
\text { será a capacidade de absorção do receptor, visto que este terá } \\
\text { dificuldades em compreender o valor do novo conhecimento e } \\
\text { aplicá-lo. }\end{array}$ & $\begin{array}{l}\text { - Cohen e Levinthal } \\
(1990) \\
\text { - Dietricks e Cool } \\
(1989)\end{array}$ \\
\hline & $\begin{array}{l}\text { Falta de } \\
\text { capacidade de } \\
\text { retenção do } \\
\text { receptor }\end{array}$ & $\begin{array}{l}\text { Refere-se à capacidade do receptor de institucionalizar o } \\
\text { conhecimento adquirido durante a transferência e aplicá-lo. }\end{array}$ & $\begin{array}{l}\text { - Glaser et al.(1983) } \\
\text { - Druckman e Bjork } \\
\text { (1991) } \\
\text { - Rogers (1983) } \\
\text { - Nord e Tucker } \\
\text { (1987) } \\
\text { - Goodman e Dean } \\
\text { (1982) } \\
\text { - Zaltman et al.(1973) }\end{array}$ \\
\hline \multirow[t]{2}{*}{$\begin{array}{l}\text { Características } \\
\text { do Contexto da } \\
\text { Transferência }\end{array}$} & $\begin{array}{l}\text { Contexto } \\
\text { Organizacional } \\
\text { Estéril }\end{array}$ & $\begin{array}{l}\text { O contexto organizacional pode influenciar na transferência de } \\
\text { conhecimento. O contexto que busca promover a transferência é } \\
\text { caracterizado como fértil, já aquele que impossibilita a } \\
\text { transferência é caracterizado como estéril. }\end{array}$ & $\begin{array}{l}\text { - Bower (1970) } \\
\text { - Burgelman (1983) } \\
\text { - Ghoshal e Bartlett } \\
(1994)\end{array}$ \\
\hline & $\begin{array}{l}\text { Difícil } \\
\text { relacionamento } \\
\text { entre a fonte e } \\
\text { o receptor }\end{array}$ & $\begin{array}{l}\text { A transferência de conhecimento se desenvolve por meio de um } \\
\text { processo interativo. Portanto, o relacionamento entre fonte e } \\
\text { receptor pode influenciar na transferência de maneira positiva } \\
\text { como negativa. É necessário que haja uma boa comunicação e } \\
\text { colaboração de ambas as partes. }\end{array}$ & $\begin{array}{l}\text { - Nonaka (1994) } \\
\text { - Arrow (1974) } \\
\text { - Marsden (1990) }\end{array}$ \\
\hline
\end{tabular}

Fonte: Adaptado de Szulanski (1995, 1996) 


\section{ASPECTOS METODOLÓGICOS}

Foi realizado um estudo exploratório descritivo, com abordagem quantitativa (CRESWELL, 1994). Como instrumento de coleta de dados utilizou-se um questionário elaborado segundo as definições das nove barreiras presentes na transferência do conhecimento, apresentadas por SZULANSKI em seus artigos publicados em 1995 e 1996. Fez-se uso de uma escala tipo likert de 6 pontos, sendo que 1 representa total discordância e 6 total concordância.

O objetivo do instrumento foi identificar quais as principais barreiras presentes na transferência do conhecimento no processo de ensino-aprendizagem durante a orientação de trabalhos de conclusão de um curso de graduação em Ciências Contábeis

$\mathrm{H} 0$ = Conhecimento prévio sobre $\mathrm{o}$ desenvolvimento de pesquisas acadêmicas reduz barreiras na transferência de conhecimento na relação entre orientador e aluno.

Para Szulansky (1995), a capacidade de absorção do conhecimento é devida, principalmente, ao conhecimento préexistente, e se manifesta em sua capacidade de avaliar, assimilar e aplicar o novo conhecimento com sucesso, promovendo a redução de barreiras.

Após o desenvolvimento de uma primeira versão do questionário, este foi submetido à avaliação de um professor pós- doutor especialista na área. A segunda versão do questionário foi submetida a um pré-teste com cinco alunos da população pesquisada, com o objetivo de se identificar possíveis problemas de interpretação quanto aos questionamentos. Alterações foram realizadas em algumas assertivas.

Os questionários foram respondidos pelos formandos de um curso de graduação em Ciências Contábeis de uma IES Privada localizada no Estado de Minas, no mês de abril de 2010. Todos os alunos se encontravam na fase de desenvolvimento de seu TCC - Trabalho de Conclusão de Curso. Nesta IES o TCC trata-se de uma monografia. O aluno deverá realizar uma pesquisa de campo, utilizando o método qualitativo e/ou quantitativo.

A população pesquisada é composta por 96 alunos. Obteve-se ao final uma amostra de 82 questionários respondidos.

Para a mensuração dos dados, utilizouse o software de análises estatísticas SPSS (PASW Statistics), versão 15. Devido ao fato da amostra ser pequena e a distribuição de valores da população não ser normal, fez-se uso do teste não paramétrico Mann-Whitney. Este teste é utilizado para aceitar a hipótese nula que afirma que as médias da população são as mesmas para os dois grupos (HAIR et $a l, 2005)$.

No presente estudo, o Grupo1 (GI) refere-se aos alunos que possuem conhecimento prévio sobre o 
desenvolvimento de pesquisas acadêmicas e o Grupo 2 (G2) refere-se aos alunos que não possuem conhecimento prévio.

Adotou-se um nível de significância de 10\% (HAIR et al,2005). Portanto:

Nível de significância $>0,10$ (distribuições iguais) $=$ hipótese não confirmada.

Nível de significância $<0,10$ (distribuições diferentes) $=$ hipótese confirmada.

\section{ANÁLISE E INTERPRETAÇÃO DOS RESULTADOS}

\subsection{Dados Demográficos}

As variáveis de caracterização dos respondentes evidenciaram que a maioria é do gênero feminino $(57,7 \%)$, se encontram na faixa etária entre 22 a 23 anos (30,8\%), atuando em sua área de formação $(42,3 \%)$.

\subsection{Resultados do Teste Não Paramétrico Mann-Whitney}

Na Tabela 1, são apresentados os 17 atributos do instrumento, o ranking do Grupo 1 (G1) e do Grupo 2 (G2), o valor de significância e a barreira referente a cada atributo

Tabela 1 - Resultado do teste não paramétrico Mann-Whitney

\begin{tabular}{|c|c|c|c|c|c|}
\hline & & $\begin{array}{c}\text { G 1 } \\
\text { SIM } \\
\text { Rank }\end{array}$ & $\begin{array}{l}\text { G } 2 \\
\text { NÃOO } \\
\text { Rank }\end{array}$ & Signif & Resultado \\
\hline & \multicolumn{5}{|c|}{ ATRIBUTOS ASSOCIADOS À AMBIGUIDADE CAUSAL } \\
\hline 1 & $\begin{array}{c}\text { O conhecimento transmitido pelo meu orientador é o } \\
\text { principal subsidio para o desenvolvimento de minha } \\
\text { pesquisa. }\end{array}$ & 51.24 & 45.66 & 0.397 & NS \\
\hline \multirow[t]{2}{*}{2} & $\begin{array}{l}\text { Os livros, os artigos e os manuais metodológicos que li, } \\
\text { são o principal subsidio para o desenvolvimento de minha } \\
\text { pesquisa }\end{array}$ & 51.49 & 42.61 & 0.178 & NS \\
\hline & \multicolumn{5}{|c|}{ ATRIBUTOS ASSOCIADOS Å FALTA DE PROVA DE UTILIDADE DO CONHECIMENTO DA FONTE } \\
\hline 3 & $\begin{array}{l}\text { As experiências e o conhecimento transmitidos pelo meu } \\
\text { orientador sobre o assunto que estou abordando, poderão } \\
\text { ser aplicados no contexto da minha pesquisa. }\end{array}$ & 52.36 & 41.73 & 0.104 & NS \\
\hline \multirow[t]{2}{*}{4} & $\begin{array}{l}\text { O método de pesquisa sugerido pelo meu orientador é o } \\
\text { mais adequado para o contexto do meu estudo. }\end{array}$ & 49.84 & 48.32 & 0.809 & NS \\
\hline & \multicolumn{5}{|c|}{ ATRIBUTOS ASSOCIADOS Å FALTA DE MOTIVAÇÃO DA FONTE } \\
\hline 5 & $\begin{array}{l}\text { O meu orientador está sempre disposto a transferir suas } \\
\text { experiências e conhecimentos em nossos encontros para } \\
\text { orientação. }\end{array}$ & 49.22 & 52.73 & 0.583 & NS \\
\hline 6 & $\begin{array}{l}\text { O meu orientador está sempre motivado para dar sugestões } \\
\text { e esclarecer minhas dúvidas sobre o desenvolvimento de }\end{array}$ & 48.32 & 55.86 & 0.250 & NS \\
\hline
\end{tabular}




\begin{tabular}{|c|c|c|c|c|c|}
\hline & minha pesquisa. & & & & \\
\hline & \multicolumn{5}{|c|}{ ATRIBUTOS ASSOCIADOS À FALTA DE CONFIABILIDADE PERCEBIDA DA FONTE } \\
\hline 7 & $\begin{array}{c}\text { O meu orientador possui o conhecimento necessário sobre } \\
\text { o assunto que irei abordar em meu estudo. }\end{array}$ & 51.05 & 43.83 & 0.273 & NS \\
\hline \multirow[t]{2}{*}{8} & $\begin{array}{c}\text { O meu orientador possui o conhecimento necessário sobre } \\
\text { como desenvolver uma pesquisa. }\end{array}$ & 52.05 & 42.82 & 0.153 & NS \\
\hline & \multicolumn{5}{|c|}{ ATRIBUTOS ASSOCIADOS Ȧ FALTA DE MOTIVAÇÃO DO RECEPTOR } \\
\hline \multirow[t]{2}{*}{9} & $\begin{array}{c}\text { Fico motivado para aplicar as experiências e os } \\
\text { conhecimentos que são transmitidos pelo meu orientador } \\
\text { em meu esstudo. }\end{array}$ & 53.04 & 39.36 & 0.034 & S \\
\hline & \multicolumn{5}{|c|}{ ATRIBUTOS ASSOCIADOS À FALTA DE CAPACIDADE DE ABSORÇÃO DO RECEPTOR } \\
\hline \multirow[t]{2}{*}{10} & $\begin{array}{l}\text { Consigo avaliar, assimilar e aplicar as experiências e os } \\
\text { conhecimentos transmitidos pelo meu orientador. }\end{array}$ & 54.03 & 35.91 & 0.006 & S \\
\hline & \multicolumn{5}{|c|}{ ATRIBUTOS ASSOCIADOS À FALTA DE CAPACIDADE DE RETENÇÃO DO RECEPTOR } \\
\hline \multirow[t]{2}{*}{11} & $\begin{array}{c}\text { Sinto-me capaz de aplicar as experiências e os } \\
\text { conhecimentos transmitidos pelo meu orientador em outras } \\
\text { pesquisas futuras. }\end{array}$ & 52.05 & 38.59 & 0.036 & S \\
\hline & \multicolumn{5}{|c|}{ ATRIBUTOS ASSOCIADOS AO CONTEXTO ORGANIZACIONAL ESTÉRIL } \\
\hline 12 & $\begin{array}{c}\text { Tenho facilidade para desenvolver o meu estudo, pois } \\
\text { minha IES estimula a pesquisa (ex: congressos de iniciação } \\
\text { científica). }\end{array}$ & 52.21 & 39.55 & 0.056 & $\mathrm{~S}$ \\
\hline \multirow[t]{2}{*}{13} & $\begin{array}{l}\text { Os meus professores estimulam a pesquisa em suas } \\
\text { disciplinas (ex: desenvolvimento de artigos científicos), } \\
\text { por isso tenho facilidade para desenvolver o meu estudo }\end{array}$ & 52.85 & 40.02 & 0.054 & $\mathrm{~S}$ \\
\hline & \multicolumn{5}{|c|}{ ATRIBUTOS ASSOCIADOS AO DIFÍCIL RELACIONAMENTO ENTRE A FONTE E O RECEPTOR } \\
\hline 14 & $\begin{array}{c}\text { Existe uma relação de cordialidade entre meu orientador e } \\
\text { eu. }\end{array}$ & 51.97 & 43.11 & 0.180 & NS \\
\hline 15 & Existe uma relação de empatia entre meu orientador e eu. & 52.81 & 40.16 & 0.059 & $\mathrm{~S}$ \\
\hline 16 & A relação entre eu e meu orientador é conflituosa. & 51.12 & 46.09 & 0.410 & NS \\
\hline 17 & $\begin{array}{c}\text { Eu apresento resistência em aceitar as sugestões do meu } \\
\text { orientador. }\end{array}$ & 48.84 & 54.05 & 0.416 & NS \\
\hline
\end{tabular}

Fonte: Elaborado pelo autor

\section{Legenda:}

Resultado = NS (Não Significante); S (Significante) $;$

De acordo com os resultados obtidos pelo teste não paramétrico, observou-se que o conhecimento prévio não promove a redução da barreira "ambiguidade causal". Os alunos que possuem conhecimento prévio sobre como elaborar pesquisas acadêmicas, como aqueles que não possuem, avaliaram os atributos igualmente. A ambigüidade causal ocorre quando não se consegue determinar, exatamente, quais foram as razões para o sucesso ou fracasso, qual foi a verdadeira fonte do conhecimento. Não é possível identificar, com precisão, qual foi a melhor prática (SZULANSKI, 1995).

Quanto à barreira "falta de prova de utilidade de conhecimento da fonte", o 
conhecimento prévio não promove a sua redução. Ambos os alunos avaliaram os atributos igualmente. De acordo com Szulanski (1995), quando a alegação de que o conhecimento será eficaz em resolver os problemas do receptor for parcialmente comprovada, será difícil induzir o receptor a se engajar na transferência.

Em relação à barreira "falta de motivação da fonte", o conhecimento prévio não influi na redução dessa barreira. Os alunos que possuem conhecimento prévio como aqueles que não possuem, avaliaram os atributos igualmente. Para Szulanski (1995), uma fonte de conhecimento pode relutar em dividir conhecimento crucial por temer perder a posse ou uma posição de privilégio, pode relutar por pensar que não será adequadamente recompensada por dividir o seu conhecimento, ou simplesmente, poderá não estar muito inclinada a dedicar tempo e recursos para apoiar a transferência.

O conhecimento prévio não reduz a barreira "falta de confiabilidade percebida da fonte". Os alunos que possuem conhecimento prévio como aqueles que não possuem avaliaram os atributos igualmente. Quando a fonte não é considerada digna de confiança ou reconhecimento, a transferência de conhecimento desta fonte será mais difícil, além de seus exemplos e conselhos provavelmente serem desafiados ou não aplicados (SZULANSKI, 1996).
O conhecimento prévio promove a redução da barreira "motivação do receptor". O grupo de alunos que possui conhecimento prévio apresentou uma distribuição maior no ranking em relação àqueles que não possuem. Portanto, os alunos que possuem conhecimento prévio tendem a se sentir mais motivados para aplicar os conhecimentos e as experiências transmitidos pelo orientador. A falta de motivação pode resultar em letargia, passividade, aceitação simulada, sabotagem oculta, ou rejeição aberta da implementação e uso do novo conhecimento (SZULANSKI, 1995).

Quanto à barreira "falta de capacidade de absorção do receptor" o conhecimento prévio influi em sua redução, confirmando a hipótese de (SZULANSKI, 1995 e 1996), que a capacidade de absorção está relacionada à quantidade de conhecimento prévio sobre o assunto que o receptor possui. Os alunos que possuem conhecimento prévio tendem a absorver mais facilmente os conhecimentos transmitidos por seus orientadores. Receptores podem ser incapazes de explorar fontes externas de conhecimento, eles podem carecer de capacidade de absorção (COHEN e LEVINTHAL, 1990). Tal capacidade é devida, principalmente, ao seu estoque de conhecimento pré-existente e se torna manifesta em sua capacidade de avaliar, assimilar e aplicar o novo conhecimento com sucesso (SZULANSKI, 1996). 
O conhecimento prévio também influi na redução da barreira "capacidade de retenção do receptor". Os alunos com conhecimento prévio tendem a se sentir capazes de aplicar as experiências e conhecimentos transmitidos pelo seu orientador em outras pesquisas futuras. A habilidade de um receptor de institucionalizar o uso do novo conhecimento reflete sua capacidade 'retentora'. $\mathrm{Na}$ ausência de tal capacidade, dificuldades iniciais durante a internalização do conhecimento recebido podem se tornar uma desculpa para descontinuar o seu uso, e quando possível, voltar-se para o antigo status quo (SZULANSKI, 1996).

Quanto à barreira "contexto organizacional estéril", os alunos com conhecimento prévio tendem a distinguir um contexto organizacional fértil de um estéril em relação àqueles que não possuem. Estes alunos tendem a sentir maior facilidade em desenvolver seu TCC devido ao conhecimento absorvido durante as atividades de pesquisa promovidas pela IES, como Congressos de Iniciação Científica e o desenvolvimento de artigos científicos exigidos como trabalhos obrigatórios pelos professores. Acredita-se que essa cultura de estímulo à pesquisa que está sendo compartilhada pelos alunos, irá facilitar ainda mais a transferência de conhecimento (ARGOTE e INGRAM, 2000), como influenciar no surgimento de um contexto organizacional ainda mais fértil. Um contexto organizacional estéril afeta o número de tentativas de transferência de conhecimento e o desfecho de tais tentativas (SZULANSKI, 1995 e 1996).

Em relação à barreira "dificuldade de relacionamento entre fonte e receptor", o conhecimento promove a redução da barreira apenas em relação ao atributo empatia. Os alunos com conhecimento prévio tendem a possuir uma relação de maior empatia com seus orientadores em relação àqueles que não possuem conhecimento prévio. Um árduo relacionamento entre receptor e fonte poderá criar dificuldades na transferência do conhecimento (SZULANSKI, 1995 e 1996).

\section{CONSIDERAÇÕES FINAIS}

O propósito do presente estudo foi identificar quais as barreiras presentes na transferência de conhecimento no processo de orientação de trabalhos de conclusão na visão dos formandos de um curso de graduação em Ciências Contábeis.. Considerou-se como hipótese que o conhecimento prévio sobre o desenvolvimento de pesquisas acadêmicas, reduz barreiras na transferência de conhecimento na relação entre orientador e aluno.

Acredita-se que o propósito deste estudo foi cumprido. Por meio da literatura específica foi possível desenvolver uma 
proposta de instrumento que permitisse confirmar ou não esta premissa.

Observou-se que o conhecimento prévio não reduz as barreiras "ambigüidade causal", "falta de prova de utilidade do conhecimento da fonte", "falta de motivação da fonte" e "falta de confiabilidade percebida da fonte".

No entanto, identificou-se que o conhecimento prévio tende a reduzir as barreiras "falta de motivação do receptor", "falta de capacidade de absorção do receptor" e "falta de capacidade de retenção do receptor"

Quanto à barreira "contexto organizacional estéril" os alunos que possuem conhecimento prévio conseguem distinguir um contexto fértil de um estéril, como reconhecessem a importância do conhecimento absorvido neste contexto. Acredita-se que essa cultura compartilhada sobre a importância da pesquisa irá influenciar em uma transferência mais efetiva como no surgimento de um contexto organizacional ainda mais fértil.

Em relação à barreira "difícil relacionamento entre fonte e receptor", os alunos que possuem conhecimento prévio tendem a possuir uma relação de maior empatia com os seus orientadores em relação àqueles que não possuem conhecimento prévio. Acredita-se que a falta de empatia deve-se ao fato do conhecimento pré-existente do receptor facilitar a absorção como a institucionalização do conhecimento. Implicitamente, está falta de empatia pode se tratar, na realidade, de uma "resistência" devida as dificuldades que estes alunos possuem em assimilar o discurso do receptor.

É importante ressaltar que para se obter maior confiabilidade em relação à proposta deste estudo, novas pesquisas deverão ser realizadas, em diferentes contextos, visando confirmar os resultados apresentados bem como complementá-los.

Quanto às contribuições esperadas para as IESs, acredita-se que os resultados abordaram questões importantes que merecem reflexão, como a criação de uma cultura que incentive a pesquisa e a importância do conhecimento, os aspectos relacionados a absorção e institucionalização do conhecimento pelos alunos e o relacionamento entre professor e aluno que irá influenciar, consideravelmente, no processo de ensino-aprendizagem.

Como sugestão final, recomenda-se às IESs o oferecimento de atividades extraclasses (congressos, cursos de extensão de curta duração, palestras, oficinas, entre outros eventos) sobre assuntos relacionados às disciplinas da matriz curricular, preferencialmente, antes que estas sejam oferecidas. O conhecimento prévio evita a sensação de "campo desconhecido" facilitando a absorção do conhecimento. 


\section{REFERÊNCIAS}

ABREU, Maria C.; MASETTO, Marcos T. O professor universitário em aula : prática e princípios teóricos. São Paulo : MG Ed. Associados, 1983.

ALAVI, M.; LEIDNER, D. E. Review; knowledge management and knowledge management systems: conceptual foundations and research issues. MIS Quarterly, Vol. 25, n. 1 p. 107-136, March, 2001.

ARGOTE, L.; INGRAM, Paul. Knowledge transfer: a basis for competitive advantage in firms. Organizational Behavior and Human Decision Process. 82(1), p. 150-169. May, 2000.

ARROW, K. Economic welfare and the allocation of resources for invention. In: NELSON, R. The rate and direction of inventive activity. Princeton: Princeton University Press, 1962.

BELL, D. The coming of post-industrial society: a venture in social forecasting. New York: Basic Books, 1973.

BERGER,P., LUCKMANN,T. A construção social da realidade. Petrópolis: Vozes. 1993.

BRONOWSKI, J. As origens do conhecimento e da imaginação. Brasília: UNB, 1997.

COHEN, W. M.; LEVINTHAL, Daniel. A. Absorptive capacity; a new perspective on learning and innovation. Administrative Science Quarterly, 35, p. 128-152, 1990.

COLLINS, H. M. The structure of knowledge. Social Research, v. 60, n. 1, Spring, 1993.

CONNELL, N. A. D.; KLEIN, J. H. ; POWELL, P. L. It's tacit knowledge but not as we know it: redirecting the search for knowledge. The Journal of the Operational Research Society. 54(2), Special Issue:
Knowledge Management and Intellectual Capital. P. 140-152, Feb, 2003.

CHOO, C. W. A organização do conhecimento. São Paulo: SENAC, 2003.

CRESWELL, J.W. Research design; Qualitative and quantitative approaches. Sage Publications, Inc.: 1994.

DAVENPORT, T. H.; PRUSAK, L. Working Knowledge - How organizations manage what they know, $1^{\text {a }}$ Edição, Harvard Business School Press, 1998.

DIXON, N. M. Common knowledge: how companies thrive by sharing what they know. Boston: Harvard Business School Press, 2000.

DRUCKER, P. F. Sociedade PósCapitalista. São Paulo: Pioneira, 1995, 4ed.

DRUCKER, P. F. Desafios gerenciais para o século XXI. São Paulo: Pioneira, 2000.

HAIR JR., J.F.; BABIN, B.; MONEY, A.H.; SAMOUEL, P. Fundamentos de métodos de pesquisa em Administração. Porto Alegre: Bookman, 2005.

NAISBITT, J. Megatrends. New York:

Warner Books, 1982.

MACOHON, E. R. O ensino de administração no curso de ciências contábeis da Universidade estadual do centrooeste/Unicentro - campus universitário de Irati/PR. In: SIMPEP - Simpósio de Engenharia de Produção, 2006, Bauru. XIII SIMPEP, 2006.

NONAKA, I.; TAKEUCHI, H. Criação de conhecimento na empresa: Como as empresas japonesas geram a dinâmica da inovação. Rio de janeiro: Campus, 1997.

NOOTEBOOM, B.; GILSING, V. Coevolution of routines: exploration \& exploitation in the multimedia industry. Conference 'Empirical Research on Routines in Business and Economics, Odensee, Denmark. 2002 
MATUSIK, S. F. "Managing Public and Private Firm Knowledge within the context of Flexible Firm Boundaries", In: Choo, C. W.; Bontis, N. (eds.), The strategic management of intellectual capital and organizational knowledge, Oxford

University Press, New York, 2002.

O`DELL, C.J.;GRAYSON, C. If only we knew what we know. New York: Free Press, 1998.

SANTIAGO JUNIOR, J. R. S.Gestão do conhecimento: a chave para o sucesso empresarial. São Paulo: Novatec, 2004.

SENGE, P. The fifth discipline: the art and practice of the learning organization. New York: Doubleday, 1990.

SHAW, R.; PERKINS, D. Ensinar as Organizações a Aprender: O Poder dos Fracassos Produtivos. In: NADLER, David. e outros. Arquitetura Organizacional. Rio de Janeiro: Campus, 1993.

SZULANSKI, G. Unpacking Stickiness: an Empirical Investigation of The Barriers to transfer best practice inside the firm.

Academy of Management Proceedings, $p$. 437-441, 1995.

SZULANSKI, G. Exploring internal stickness: impediments to the transfer of the best practice within the firm. Strategic Management Journal. 17 - Winter Special Issue, p. 27-43, 1996.

SZULANSKI, Gabriel. Sticky knowledge: barriers to knowing in the firm. London: Sage, 2003.

TACHIZAWA, T; ANDRADE, R.O.B.Gestão de instituições de ensino. Ed. FGV: Rio de Janeiro, 2002

TOFLER, A. The third wave. New York:

Willian Morrow, 1980. 